\title{
Analisis Pengaruh Daya Tarik Iklan, Kualitas Pesan Iklan, dan Selebriti Endorser terhadap Keputusan Pembelian Uniqlo
}

\author{
Safira Fitri' ${ }^{1}$, Rezi Erdiansyah ${ }^{2}$ \\ ${ }^{1}$ Fakultas Ilmu Komunikasi Universitas Tarumanagara \\ Email: safirafitrri@gmail.com \\ ${ }^{2}$ Fakultas Ilmu Komunikasi Universitas Tarumanagara* \\ Email: rezie@fikom.untar.ac.id
}

Masuk tanggal : 15-12-2021, revisi tanggal : 06-01-2022, diterima untuk diterbitkan tanggal : 16-01-2022

\begin{abstract}
The objectives of this study are: 1) To find out how much influence the level of advertising attractiveness has on the purchasing decisions of UNIQLO consumers on Instagram. 2) To find out how much influence the quality of advertising messages has on purchasing decisions of UNIQLO consumers on Instagram. 3) To find out how significant the influence of celebrity endorser use is on UNIQLO consumer purchasing decisions on Instagram. This research uses a quantitative approach, and the analysis used is multiple linear regression. The research sample used was 100 people who actively use Instagram. There are three variables in this study, namely: the attractiveness of the ad, the quality of the advertising message, also the celebrity endorser. The results of this study indicate that the variables of advertising attractiveness and celebrity endorsers have a positive effect on purchasing decisions. Meanwhile, the variable quality of advertising messages has no effect on purchasing decisions of UNIQLO consumers on Instagram.
\end{abstract}

Keywords: attractiveness of ads, celebrity endorsers, purchase decisions, quality of advertising messages

\begin{abstract}
Abstrak
Tujuan dari penelitian oleh penulis yaitu: 1) Agar mengetahui seberapa besar pengaruh tingkat daya tarik iklan atas keputusan pembelian konsumen UNIQLO di Instagram. 2) Agar mengetahui besar pengaruh kualitas pesan iklan atas keputusan pembelian konsumen UNIQLO di Instagram. 3) Untuk mengetahui seberapa signifikan pengaruh penggunaan selebriti endorser atas keputusan pembelian konsumen UNIQLO di Instagram. Di samping itu, peneliti dalam penelitian menggunakan metode kuantitatif, dan analisis yang digunakan merupakan regresi linear berganda. Sampel penelitian diambil sebanyak 100 orang yang aktif menggunakan Instagram. Variabel di penelitian berikut memiliki sebanyak tiga variabel, yaitu: daya tarik iklan, kualitas pesan iklan, dan selebriti endorser. Hasil penelitian pun menunjukkan variabel daya tarik iklan serta selebriti endorser menghasilkan pengaruh positif atas keputusan pembelian. Sementara, variabel kualitas pesan iklan tidak memiliki pengaruh terhadap keputusan pembelian konsumen UNIQLO di Instagram.
\end{abstract}

Kata Kunci: daya tarik iklan, keputusan pembelian, kualitas pesan iklan, selebriti endorser

\section{Pendahuluan}

Seiring berjalannya waktu, revolusi dalam bidang informasi, teknologi dan komunikasi terus berjalan hingga mencapai perkembangan besar bagi masyarakat dunia. Hal ini terlihat semakin banyaknya orang yang menggunakan mobile phone dengan fitur canggih atau disebut sebagai smartphone. Di Indonesia sendiri, fenomena 
revolusi mobile phone turut memberikan pengaruh yang cukup besar bagi berbagai bidang. Pengaruh tersebut tentunya memberikan dampak keuntungan bagi banyak pihak. Di samping itu, terdapat aplikasi-aplikasi yang dapat digunakan untuk berinteraksi antara pengguna internet satu dengan lainnya, hal ini dikenal dengan sebutan media sosial. Berdasarkan penjelasan Kaplan dan Haenlein (2010), media sosial merupakan sejumlah aplikasi yang berbasis internet dan dibuat denganan pondasi ideologi dan teknologi dari Web 2.0, yang memberi akses pembuatan serta pertukaran User Generated Content (UGC).

Adapun perluasan media komunikasi di zaman digital seperti saat ini sangat cepat. Media sosial yang semula hanya digunakan sebagai sebuah wadah mengekspresikan diri maupun bertukar informasi, kini justru tumbuh menjadi sarana digital marketing atau pun advertising yang sangat ramai digunakan. Instagram menjadi salah satu media sosial terbesar yang digemari masyarakat. Ramainya pengguna Instagram membuat aplikasi tersebut turut digunakan sebagai media pemasaran online untuk mengiklankan brand mau pun produk dan jasa oleh banyaknya pengusaha kecil hingga perusahaan besar.

Menurut Belch dan Belch (dalam Morrisan, 2010), daya tarik iklan merupakan sesuatu yang digunakan untuk membuat produk dari perusahaan menarik dan diperhatikan oleh konsumen. Kemudian, kualitas pesan iklan, sebagaimana penjelasan Purianti dan Liana (2004), ialah harus memperhatikan apa yang akan dikatakan (isi pesan), bagaimana mengatakannya secara logis (struktur pesan), bagaimana mengatakannya secara simbolis (format iklan), dan siapa seharusnya yang mengatakan (sumber pesan), hingga penggunaan selebriti endorser dalam iklan yang menjadi bagian dari faktor penting yang mempengaruhi keberhasilan dari iklan yang dibuat dengan tujuan tertentu

UNIQLO adalah salah satu brand besar yang menggunakan media sosial Instagram sebagai sarana promosi atau beriklan. Dalam hal pembuatan iklan, terdapat beberapa hal penting di antaranya meliputi daya tarik iklan, kualitas pesan iklan, serta penggunaan selebriti endorser yang dapat mempengaruhi keputusan pembelian oleh konsumen. Dengan jumlah sebanyak 1 juta followers di Instagram, UNIQLO percaya bahwa dari kalangan konsumen, terutama kalangan muda yang peka terhadap mode cenderung akan bersemangat dan mengunggah segala sesuatu mengenai produk terbaru mau pun acara terkini di media sosial. Dalam berpromosi, hal ini akan mempengaruhi peningkatan dan keputusan pembelian konsumen.

Oleh sebab itu, penulis tertarik melakukan penelitian guna mengetahui seberapa signifikan pengaruh atas daya tarik iklan, kualitas pesan iklan, serta selebriti endorser yang digunakan oleh UNIQLO terhadap keputusan pembelian oleh konsumennya di Instagram.

\section{Metode Penelitian}

Penelitian ini menggunakan pendekatan kuantitatif dalam menganalisa data penelitian. Penelitian kuantitatif menurut Mohammad Mulyadi (2016) yakni penelitian yang mengumpulkan data menggunakan desain eksplanasi, di mana objek yang ditelaah penelitian eksplanasi yaitu untuk menguji hubungan yang di hipotesiskan dari antar-variabel. Penelitian kuantitatif adalah penelitian secara sistematis, terencana, dan terstruktur terhadap bagian-bagian dan fenomena serta hubungan-hubungannya dengan jelas sejak awal hingga akhir penelitian. Metode kuantitatif ini disebut 
demikian karena data penelitian berupa angka-angka dan analisis menggunakan stastitik (Sugiyono, 2010).

Penulis menggunakan teknik analisis regresi linear berganda. Regresi linear berganda, yakni bentuk regresi linier yang mengkaitkan sejumlah variabel tidak terikat atau predictor. Metode ini dimaksudkan untuk menguji keterkaitan dari variabel terikat (Y) pada satu atau beberapa variabel tidak terikat (predictor). Di samping itu, disebut sebagai variabel prediktor karena variabel ini diharapkan dapat memprediksikan nilai variabel respon. Biasanya variabel terikat diisyaratkan dengan $\mathrm{Y}$, sedangkan pada variabel tidak terikat diisyaratkan dengan $\mathrm{X}$.

Adapun penelitian yang dilakukan penulis menggunakan cara menyebarluaskan kuesioner untuk para pengguna Instagram sebagai populasi di dalam penelitian, khususnya pengikut aktif Instagram Uniqlo. Teknik sampling yang digunakan adalah simple random sampling yang menurut Sugiyono (2015) adalah sampel yang diambil secara acak tanpa memperhatikan strata dari suatu populasi.

\section{Hasil Temuan dan Diskusi}

\section{Uji Validitas}

Tabel 1. Uji Validitas Variabel Daya Tarik Iklan, Kualitas Pesan Iklan, serta Selebriti Endorser (X)

\begin{tabular}{|c|c|c|c|}
\hline \multicolumn{4}{|c|}{ Correlations $^{\text {a }}$} \\
\hline & & TS & Keterangan \\
\hline \multirow{3}{*}{ X_P1 } & $\begin{array}{c}\text { Pearson } \\
\text { Correlation } \\
\end{array}$ & .717 & \multirow{3}{*}{ Valid } \\
\hline & Sig. (2-tailed) & .000 & \\
\hline & $\mathrm{N}$ & 100 & \\
\hline \multirow{3}{*}{ X_P2 } & $\begin{array}{c}\text { Pearson } \\
\text { Correlation }\end{array}$ & $.556 ”$ & \multirow{3}{*}{ Valid } \\
\hline & Sig. (2-tailed) & .000 & \\
\hline & $\mathrm{N}$ & 100 & \\
\hline \multirow{3}{*}{ X_P3 } & $\begin{array}{c}\text { Pearson } \\
\text { Correlation }\end{array}$ & $.714 "$ & \multirow{3}{*}{ Valid } \\
\hline & Sig. (2-tailed) & .000 & \\
\hline & $\mathrm{N}$ & 100 & \\
\hline \multirow{3}{*}{ X_P4 } & $\begin{array}{c}\text { Pearson } \\
\text { Correlation }\end{array}$ & $.405 ”$ & \multirow{3}{*}{ Valid } \\
\hline & Sig. (2-tailed) & .000 & \\
\hline & $\mathrm{N}$ & 100 & \\
\hline \multirow{3}{*}{ X_P5 } & $\begin{array}{c}\text { Pearson } \\
\text { Correlation } \\
\end{array}$ & $.630 ”$ & \multirow{3}{*}{ Valid } \\
\hline & Sig. (2-tailed) & .000 & \\
\hline & $\mathrm{N}$ & 100 & \\
\hline \multirow{3}{*}{ X_P6 } & $\begin{array}{l}\text { Pearson } \\
\text { Correlation }\end{array}$ & $.675^{\prime \prime}$ & \multirow{3}{*}{ Valid } \\
\hline & Sig. (2-tailed) & .000 & \\
\hline & $\mathrm{N}$ & 100 & \\
\hline
\end{tabular}


Vol. 6, No. 1, Maret 2022, Hal 154-162

\begin{tabular}{|c|c|c|c|}
\hline \multirow{3}{*}{ X_P7 } & $\begin{array}{c}\text { Pearson } \\
\text { Correlation }\end{array}$ & $.510 "$ & \multirow{3}{*}{ Valid } \\
\hline & Sig. (2-tailed) & .000 & \\
\hline & $\mathrm{N}$ & 100 & \\
\hline \multirow{3}{*}{ X_P8 } & $\begin{array}{c}\text { Pearson } \\
\text { Correlation }\end{array}$ & $.734 ”$ & \multirow{3}{*}{ Valid } \\
\hline & Sig. (2-tailed) & .000 & \\
\hline & $\mathrm{N}$ & 100 & \\
\hline \multirow{3}{*}{ X_P9 } & $\begin{array}{c}\text { Pearson } \\
\text { Correlation }\end{array}$ & $.710 ”$ & \multirow{3}{*}{ Valid } \\
\hline & Sig. (2-tailed) & .000 & \\
\hline & $\mathrm{N}$ & 100 & \\
\hline \multirow{4}{*}{ X_P10 } & $\begin{array}{c}\text { Pearson } \\
\text { Correlation }\end{array}$ & $.692 ”$ & \multirow{4}{*}{ Valid } \\
\hline & Sig. (2-tailed) & .000 & \\
\hline & $\mathrm{N}$ & 100 & \\
\hline & $\begin{array}{c}\text { Pearson } \\
\text { Correlation }\end{array}$ & 1 & \\
\hline
\end{tabular}

TS

Sig. (2-tailed)

Sumber: Hasil Pengolahan Data SPSS 23

Dari tabel 1 pernyataan mengenai daya tarik iklan, kualitas pesan iklan, serta selebriti endorser yang berjumlah 10 butir dan disebarkan kepada 100 responden dinyatakan valid.

Tabel 2. Uji Validitas Keputusan Pembelian (Y)

\begin{tabular}{|c|c|c|c|}
\hline \multicolumn{4}{|c|}{ Correlations $^{\mathrm{a}}$} \\
\hline & & $\mathrm{TS}$ & Keterangan \\
\hline \multirow{3}{*}{ Y_P1 } & Pearson Correlation & $.774 "$ & \multirow{3}{*}{ Valid } \\
\hline & Sig. (2-tailed) & .000 & \\
\hline & $\mathrm{N}$ & 100 & \\
\hline \multirow{3}{*}{ Y_P2 } & Pearson Correlation & $.758 "$ & \multirow{3}{*}{ Valid } \\
\hline & Sig. (2-tailed) & .000 & \\
\hline & $\mathrm{N}$ & 100 & \\
\hline \multirow{3}{*}{ Y_P3 } & Pearson Correlation & $.692 "$ & \multirow{3}{*}{ Valid } \\
\hline & Sig. (2-tailed) & .000 & \\
\hline & $\mathrm{N}$ & 100 & \\
\hline \multirow{3}{*}{ Y_P4 } & Pearson Correlation & $.720 "$ & \multirow{3}{*}{ Valid } \\
\hline & Sig. (2-tailed) & .000 & \\
\hline & $\mathrm{N}$ & 100 & \\
\hline \multirow{3}{*}{ Y_P5 } & Pearson Correlation & $.741 ”$ & \multirow{3}{*}{ Valid } \\
\hline & Sig. (2-tailed) & .000 & \\
\hline & $\mathrm{N}$ & 100 & \\
\hline
\end{tabular}

Sumber: Hasil Pengolahan Data SPSS 23 
Dari tabel 2 pernyataan mengenai keputusan pembelian yang berjumlah 5 butir dan disebarkan kepada 100 responden dinyatakan valid.

\section{Uji Reliabilitas}

Jumlah Cronbach's Alpha berdasarkan variabel daya tarik iklan, kualitas pesan iklan, serta selebriti endorser yang berjumlah 15 butir pernyataan dan mendapati responden sebanyak 100 orang setelah diolah dan dianalisis dengan reliability scala dengan menggunakan SPSS 23, memperoleh nilai sebagai berikut.

Tabel 3. Uji Reliabilitas Daya Tarik Iklan, Kualitas Pesan Iklan, dan Selebriti

\begin{tabular}{cc}
\multicolumn{2}{c}{ Endorser $(\mathrm{X})$} \\
\hline \multicolumn{2}{c}{ Reliability Statistics } \\
\hline Cronbach's Alpha & N of Items \\
\hline .839 & 15 \\
\hline
\end{tabular}

Sumber: Pengolahan Data SPSS 23

Berdasarkan tabel 3 maka dapat disimpulkan jumlah c=Cronbach's Alpha reliabilitas skala daya tarik iklan, kualitas pesan iklan, serta selebriti endorser menunjukkan baik, karena mendapatkan nilai alpha di atas 0,8 . Oleh sebab itu, hasilnya reliable.

Sementara, nilai cronbach's alpha keputusan pembelian dengan jumlah 5 butir pernyataan dalam skala yang mendapati responden sebanyak 100 orang setelah data diolah dan dianalisis dengan reliability scale menggunakan SPSS 23 memperoleh nilai sebagai berikut.

Tabel 4. Uji Keputusan Pembelian (Y)

\begin{tabular}{cc}
\hline \multicolumn{2}{c}{ Reliability Statistics } \\
\hline Cronbach's Alpha & N of Items \\
\hline .789 & 5 \\
\hline
\end{tabular}

Sumber: Pengolahan Data SPSS 23

Dari tabel 4 maka bisa disimpulkan, nilai Cronbach's Alpha reliabilitas skala keputusan pembelian menunjukkan skala tersebut dikatakan baik, karena mendapatkan nilai alpha di atas 0,7 . Oleh sebab itu, hasilnya reliable.

\section{Analisis Regresi Linear Berganda}

Tabel 5. Analisis Regresi Linier Berganda

\begin{tabular}{llll}
\hline \multicolumn{4}{c}{ Variables Entered/Removed $^{a}$} \\
\hline \multirow{3}{*}{ Model } & \multicolumn{1}{c}{ Variables } \\
& Variables Entered & Removed & \multicolumn{1}{c}{ Method } \\
\hline & Selebriti_Endorser, & \\
& Kualitas_Pesan_Ikla & . Enter \\
& n, & & \\
& Daya_Tarik_Iklan & \\
\end{tabular}

a. Dependent Variable: Keputusan_Pembelian

b. All requested variables entered.

Sumber: Hasil Pengolahan Data SPSS 23 (2020) 
Dari tabel 5 menjelaskan mengenai variabel Daya Tarik Iklan, Kualitas Pesan Iklan, serta Selebriti Endorser sebagai variabel independent dan Keputusan Pembelian yakni variabel dependent, sementara untuk metodenya adalah metode Enter.

Tabel 6. Analisis Regresi Linier Berganda

\begin{tabular}{|c|c|c|c|c|c|}
\hline \multicolumn{6}{|c|}{ Coefficients $^{\mathbf{a}}$} \\
\hline \multirow[b]{2}{*}{ Model } & $\begin{array}{r}\text { Unstan } \\
\text { Coeff } \\
\end{array}$ & $\begin{array}{l}\text { rdized } \\
\text { ients }\end{array}$ & $\begin{array}{c}\text { Standardized } \\
\text { Coefficients }\end{array}$ & \multirow[b]{2}{*}{$\mathrm{T}$} & \multirow[b]{2}{*}{ Sig. } \\
\hline & B & $\begin{array}{l}\text { Std. } \\
\text { Error }\end{array}$ & Beta & & \\
\hline (Constant) & 1.904 & 2.424 & & .786 & .434 \\
\hline Daya_Tarik_Iklan & .478 & .119 & .408 & 4.010 & .000 \\
\hline Kualitas_Pesan_Iklan & .084 & .070 & .091 & 1.195 & .235 \\
\hline Selebriti_Endorser & .317 & .101 & .320 & 3.142 & .002 \\
\hline
\end{tabular}

a. Dependent Variable: Keputusan_Pembelian

Sumber: Hasil Pengolahan Data SPSS 23

Dari tabel 6 memperlihatkan dari uji regresi linier berganda antara Daya Tarik Iklan (X!), Kualitas Pesan Iklan (X2), Selebriti Endorser (X3), dan Keputusan Pembelian (Y) didapatkan hasil persamaan sebagai berikut:

$$
\mathrm{Y}=1,904+0,478 \mathrm{X} 1+0,084 \mathrm{X} 2+0,317 \mathrm{X} 3
$$

\section{Uji Hipotesis}

Tabel 7. Uji T

\begin{tabular}{|c|c|c|c|c|c|c|c|}
\hline \multicolumn{8}{|c|}{ Coefficients $^{a}$} \\
\hline \multirow[b]{2}{*}{ Model } & \multicolumn{2}{|c|}{$\begin{array}{l}\text { Unstandardize } \\
\text { d Coefficients }\end{array}$} & $\begin{array}{c}\text { Standardize } \\
\mathrm{d} \\
\text { Coefficients }\end{array}$ & \multirow[b]{2}{*}{$\mathrm{T}$} & \multirow[b]{2}{*}{ Sig. } & \multicolumn{2}{|c|}{$\begin{array}{c}\text { Collinearity } \\
\text { Statistics }\end{array}$} \\
\hline & B & $\begin{array}{l}\text { Std. } \\
\text { Error }\end{array}$ & Beta & & & $\begin{array}{c}\text { Toleranc } \\
\mathrm{e}\end{array}$ & VIF \\
\hline (Constant) & 1.904 & 2.424 & & .786 & $\begin{array}{c}.43 \\
4\end{array}$ & & \\
\hline $\begin{array}{l}\text { Daya_Tarik } \\
\text { _Iklan }\end{array}$ & .478 & .119 & .408 & 4.010 & $\begin{array}{c}.00 \\
0\end{array}$ & .562 & 1.781 \\
\hline $\begin{array}{l}\text { Kualitas_Pe } \\
\text { san_Iklan }\end{array}$ & .084 & .070 & .091 & 1.195 & $\begin{array}{c}.23 \\
5\end{array}$ & .993 & 1.007 \\
\hline $\begin{array}{l}\text { Selebriti_En } \\
\text { dorser }\end{array}$ & .317 & .101 & .320 & 3.142 & $\begin{array}{c}.00 \\
2\end{array}$ & .560 & 1.786 \\
\hline
\end{tabular}

Sumber: Hasil Pengolahan Data SPSS 23 (2020)

Tabel 8. Uji F

ANOVA ${ }^{a}$

\begin{tabular}{lcrrrrr}
\hline Model & $\begin{array}{l}\text { Sum of } \\
\text { Squares }\end{array}$ & df & Mean Square & F & Sig. \\
\hline Regression & 364,412 & & 3 & 121,471 & 25,279 &, $000^{\text {b }}$ \\
\hline Residual & 461,298 & 96 & 4,805 & & \\
\hline Total & 825,710 & 99 & & & \\
\hline
\end{tabular}




\section{Pengaruh Kualitas Pesan Iklan atas Keputusan Pembelian}

Koefisien regresi kualitas pesan iklan (X2) bernilai sejumlah 0,084. Artinya adalah setiap naik satu-satuan variabel kualitas pesan iklan (X2), oleh sebab itu keputusan pembelian menurun yaitu sejumlah 0,084 satuan dan jika variabel kualitas pesan iklan (X2) diturunkan sebesar satu-satuan akan menurun kepada keputusan pembelian konsumen sebesar 0,084 satuan. Nilai uji t variabel kualitas pesan iklan (X2) memiliki nilai thitung sebesar 1,195, artinya kecil bila disejajarkan pada jumlah $\mathrm{t}$ tabel yang memiliki besaran 1,984. Adapun nilai signifikan sebesar 0,235 yang artinya besar apabila disejajarkan pada tingkat signifikansi sebesar 0,05. Ho2 diterima dan $\mathrm{Ha} 2$ ditolak. Maka kesimpulannya bahwa variabel kualitas pesan iklan tidak memiliki pengaruh atas keputusan pembelian konsumen UNIQLO di Instagram. Berdasarkan hasil uji menjelaskan kualitas pesan iklan tidak terdapat pengaruh yang positif atas keputusan pembelian.

\section{Pengaruh Selebriti Endorser atas Keputusan Pembelian}

Koefisien regresi selebriti endorser (X3) bernilai sejumlah 0,317. Artinya adalah jika naik satu-satuan variabel selebriti endorser (X3), maka keputusan pembelian konsumen akan bertambah yaitu sejumlah 0,317 satuan dan sebaliknya, jika variabel selebriti endorser (X3) diturunkan sebesar satu-satuan akan menurunkan keputusan pembelian konsumen sejumlah 0,317 satuan. Nilai uji t variabel selebriti endorser (X3) memiliki t hitung yaitu sebesar 3,142 yang artinya besar jika disejajarkan pada jumlah $\mathrm{t}$ tabel yang memiliki besara 1,984. Adapun jumlah signifikan sebesar 0,002 yang artinya kecil bila disejajarkan dengan tingkat signifikansi sebesar 0,05. Ho3 ditolak dan Ha3 diterima. Maka dapat menyimpulkan jika variabel selebriti endorser berpengaruh positif atas keputusan pembelian konsumen UNIQLO di Instagram.

Berdasarkan hasil uji, terlihatselebriti endorser menghasilkan pengaruh positif atas keputusan pembelian. Di samping itu, hasil koefisien regresi memperoleh nilai positif atau memiliki pengaruh yang sejalan, yakni jika semakin tinggi penggunaan selebriti endorser, akan semakin tinggi pula keputusan pembelian konsumen.

\section{Simpulan}

Dari hasil penelitian dan pembahasan yang telah disampaikan pada bab sebelumnya atas pengaruh daya tarik iklan, kualitas pesan iklan, dan selebriti endorser terhadap keputusan pembelian konsumen UNIQLO di Instagram, penulis dapat menyimpulkan beberapa hal sebagai berikut, yaitu:

1. Daya tarik iklan memiliki pengaruh secara positif atas keputusan pembelian konsumen UNIQLO di Instagram.

2. Kualitas pesan iklan tidak memiliki pengaruh signifikan atas keputusan pembelian konsumen UNIQLO di Instagram.

3. Selebriti endorser memiliki pengaruh secara signifikan atas keputusan pembelian konsumen UNIQLO di Instagram.

4. Variabel yang berkontribusi paling besar terhadap keputusan pembelian adalah variabel selebriti endorser dengan nilai t value sebesar 3,142. Dengan demikian keputusan pembelian konsumen UNIQLO di Instagram begitu dipengaruhi oleh selebriti endorser.

5. Hipotesis yang paling dominan dalam penelitian adalah hipotesis 1 (Ha $\mathrm{H}_{1}$ yaitu daya tarik iklan berpengaruh signifikan atas keputusan pembelian konsumen 
UNIQLO di Instagram dengan nilai t value sebesar 4,010. Dengan demikian keputusan pembelian begitu terdampak oleh daya tarik iklan serta selebriti endorser. Dalam mencapai keputusan pembelian, perlu menciptakan daya tarik iklan dan pengoptimalan selebriti endorser yang tinggi dari UNIQLO di Instagram.

\section{Ucapan Terima Kasih}

Peneliti ingin mengucapkan terima kasih kepada Fakultas Ilmu Komunikasi Universitas Tarumanagara, narasumber, serta semua pihak yang turut membantu peneliti sehingga penelitian ini dapat diselesaikan.

\section{Daftar Pustaka}

Kaplan, A., Haenlein, M. (2010). Users of the world, unite! The challenges and opportunities of social media. Business Horizons 53. (1). p. 61.

Morrisan, M. (2010). Periklanan Komunikasi Pemasaran Terpadu. Prenada Media Group.

Mulyadi, Mohammad. (2016).

Purianti dan Liana. (2004). Metode Penelitian Praktis Kuantitatif Dan Kualitatif. Jakarta: Publica Press. Strategi Menaklukan Pasar. Jakarta: PT. Gramedia Pustaka Utama.

Sugiyono. (2010). Metode Penelitian Pendidikan Pendekatan Kuantitatif, kualitatif, dan R\&D. Bandung: Alfabeta.

Sugiyono. (2015). Metode Penelitian Kombinasi (Mix Methods). Bandung: Alfabeta. 